\section{ASTRONOMÍA ESPECTACULAR Y EXTRAVÍOS DE LA GULA EN UN FESTEJO NOVOHISPANO DEL SIGLO XVIII}

\author{
JOSÉ PASCUAL BUXÓ \\ Universidad Nacional Autónoma de México \\ pbuxo@axtel.net
}

José Pascual Buxó

José Pascual Buxó es doctor en Letras por la Università degli Studi di Urbino, Italia. Profesor de la División de Estudios de Posgrado de la Facultad de Filosofía y Letras, UNAM, y fundador de la maestría en Literatura Mexicana en la Facultad de Filosofía y Letras de la Benemérita Universidad Autónoma de Puebla. Ha publicado textos canónicos como El enamorado de Sor Juana y Sor Juana Inés de la Cruz: amor y conocimiento. El resplandor intelectual de las imágenes o Est udios de emblemática y literatura novohispana.

\title{
RESUMEN
}

No sólo las cambiantes peripecias de la Guerra de Sucesión fueron causa de las manifestaciones de lealtad de los súbditos americanos, sino que con más razón eran celebrados con oficial alborozo los faustos acontecimientos de la casa real. Al igual que en la metrópoli, tales acontecimiento dieron origen a festejos de diversa índole, cuya ideación y descripción fueron encomendadas a conspicuos letrados de la Nueva España. Hoy, a pesar de la trágica dispersión de los impresos coloniales, todavía conservamos noticias de muchos de aquellos que daban cuenta, por una parte, de las victorias obtenidas por el monarca hispano sobre sus enemigos y, por el otro, se congratulaban del alumbramiento de los infantes. Para los «festivos alborozos y comunes alegrías» de la corte mexicana por el nacimiento del infante Felipe Pedro, el erudito Gil Ramírez, en colaboración con otros ingenios de la corte mexicana, imaginó un deslumbrante dispositivo simbólico, según el cual serían cada una de las divisiones de la esfera mundana, titulado Esfera mexicana... (1714), una de las principales composiciones emblemáticas del siglo.

Palabras clave: Esfera mexicana, Ilustración, festejos, Nueva España.

\section{ABSTRACT}

Not only the changeable fortunes of the War of the Spanish Succession were the cause of the manifestations of loyalty of American subjects, but were celebrated with official joy the events of the royal house. As in the metropolis, the events gave way to diverse celebrations. The conception and description of these celebrations were assigned to prominent learned of the New Spain. Today, despite the tragic spread of colonials lefleats, still we retain many of those that account for the victories of the Spanish monarch and the birth of infants. For the common festivities of the Mexico subjects for the birth of the infant Felipe Pedro, the scholar Gil Ramirez, in collaboration with other Mexican intellectuals, imagined symbolic structure, titled Esfera mexicana ( 1714 ), a major emblematic century compositions.

Keywords: Esfera mexicana, Enlightenment, New Spain, festivities. 


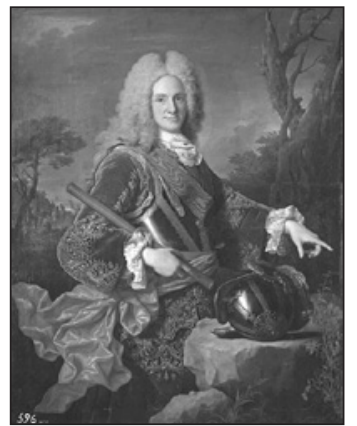

Retrato del rey Felipe $\mathrm{V}$ de España, por Jean Ranc, 1723
Astronomía espectacular y extravíos de la gula en un festejo novohispano del siglo XVIII

JOSÉ PASCUAL BUXÓ

\section{I}

El 21 de abril de 1682 -o quizá del 83- se representó en la corte mexicana una loa escrita por Sor Juana Inés de la Cruz «A los años de la Reina Nuestra Señora Doña María Luisa de Borbón» (Cfr. con Sor Juana Inés de la Cruz, III, 1955), primera esposa de Carlos II. Con ese matrimonio de la sobrina de Luis XIV con el joven y mal dotado monarca español, iniciaba el Rey Sol la trama, prolongada y sutil, que concluiría con la instalación de un príncipe de su linaje en el trono de España. Pero en su tiempo, aparte las debidas celebraciones cortesanas de aquellos regios esponsales, Sor Juana ya podía advertir las inmediatas implicaciones políticas de la poderosa alianza concertada entre Alemania, España y Francia, esto es, el reforzamiento de lo que ella misma llamó

los estrechos lazos

con que las Familias Regias

de Austria, Borbón y Valois

tan dulcemente se estrechan,

y, como consecuencia de esa «amorosa cadena», la unión política de las «partes de Europa supremas», así como las obligaciones

que en mutua correspondencia

por Francia obligan a España

y a España por Francia empeñan.

Lo que no pudo prever Sor Juana es que María Luisa moriría prematuramente sin descendencia y que Mariana de Neoburgo, la robusta alemana con quien Carlos II contrajo segundas nupcias, tampoco le daría el deseado heredero (Véase Octavio Castro, 1998). La falta de sucesión directa y la consiguiente proclamación en 1700 de Felipe de Anjou, sobrino de Luis XIV, como Felipe V de España, dejó inconformes a los partidarios de Carlos, archiduque de Austria, también aspirante al trono español, quien, a su vez, sería proclamado rey con el nombre de Carlos III (el primer Carlos III) con el beneplácito del Papa Clemente XI y la adhesión de las provincias españolas de Aragón, Valencia y Cataluña. La guerra era inevitable y los ejércitos coligados de Inglaterra, Holanda y el Imperio austro húngaro alcanzaron resonantes victorias sobre los ejércitos franceses y españoles, al punto de obligar a Felipe $\mathrm{V}$ a abandonar $\mathrm{Ma}-$ drid, pues casi toda España estaba en manos enemigas. Con todo, la inesperada fortuna de los partidarios de Felipe V les hizo salir victoriosos en las batallas de Almansa, Brihuega y Villaviciosa (1710), que acabarían por hacer triunfar la causa borbónica. En 1701 Felipe V había contraído matrimonio con María Luisa de Saboya, cuyo prematuro fallecimiento ocurrió en 1714, justamente el mismo año en que los tratados de Utrecht y Rastadt ponían fin a la Guerra de Sucesión, con notable detrimento de las posesiones borbónicas.

Con razonable oportunidad llegaban a los reinos americanos las noticias de cuanto acontecía en España, y las prensas mexicanas respondían con entusiasmo y lealtad a los faustos sucesos que la guerra deparaba a sus monarcas. Así, por citar algunos ejemplos, en 1711 el padre Miguel de Castilla, jesuita y rector de su Colegio Máximo de México, pronunció en la Iglesia Metropolitana un Elogio sepulcral a la inmortal memoria de los Españoles, que murieron en... la expulsión del exercito enemigo, segunda vez apoderado de la Corte de Madrid; Manuel de Argüello, franciscano natural de Texcoco, hizo imprimir su Acción de gracias [por] las victorias que consiguió... don Philipo $V$, y Lucas de Verdiguer, canónigo magistral y tesorero de la Iglesia Metropolitana, produjo un exaltado panegírico: México plausible... en acción de gracias, por la victoria del... Philipo Quinto... en los campos de Bribuega y Villaviciosa. Al año siguiente, el padre Joaquín Antonio de Villalobos, jesuita, maestro de retórica y teología, predicó y publicó un Sermón en acción de gracias por las victorias que en... Villaviciosa alcanzó... Phelipe $V$, y ese mismo año, pero no en México, como los anteriores, sino en Puebla, José de Torres Pezellín, franciscano, dio a luz un Sermón de acción de gracias... por la victoria que consiguió... Phelipe $V$.

Pero no sólo las cambiantes peripecias de la Guerra de Sucesión fueron causa de las manifestaciones de lealtad de los súbditos americanos, con más razón eran celebrados con oficial alborozo los faustos acontecimientos de la casa real. En 1707 nace Luis Fernando, primer hijo de Felipe V, quien por abdicación de su padre, tendría un fugaz reinado con el nombre de Luis I; en 1712 nace Felipe Pedro y, en 1713, Fernando Gabriel, el futuro Fernando VI. Al igual que en la metrópoli, tales acontecimiento dieron origen a festejos de diversa índole, cuya ideación y descripción 
fueron encomendadas a conspicuos letrados de la Nueva España. Hoy, a pesar de la trágica dispersión de los impresos coloniales, todavía conservamos noticias de muchos de aquellos que daban cuenta, por una parte, de las victorias obtenidas por el monarca hispano sobre sus enemigos y, por el otro, se congratulaban del alumbramiento de los infantes.

En ese año de 1707 ya circulaba en México la noticia de hallarse la reina encinta, y los poderes novohispanos se apresuraron a cumplir los ritos celebratorios de la monarquía: salieron entonces a luz, entre otros del mismo asunto, el sermón de Fernando de Toro Altamirano congratulándose por la «feliz noticia» de la preñez de la reina; al año siguiente Blas del Pulgar dio el Sermón... en acción de gracias... por el augustísimo parto de la reyna, y en 1709 Juan Ignacio de Castorena y Ursúa, colector de la Fama y obras póstumas de Sor Juana Inés de la Cruz y futuro obispo de Yucatán, publicó el Fruto de bendición de la Rosa de Castilla y la Flor de Lyz francesa, el rey y la reina..., metáfora leída por el amigo de la Décima Musa en el pasaje de la citada loa en que se asegura que María Luisa de Borbón, siendo «Flor de Lis Francesa», tiene por mayor timbre de gloria el haberse transmutado en «Rosa de Castilla»: idea poética y comprobación política del legítimo ingreso del linaje francés en el trono español. Y todavía en 1710 se imprimen el Sermón... en acción de gracias por el feliz nacimiento del principe de Espa$\tilde{n} a . .$. Luis Fernando, de Juan de San Miguel, así como Las tres Gracias... de la lealtad de México, donde... celebró su Aplauso por... el natalicio del... Señor D. Phelipe Pedro... de Diego Ambrosio de Orcolaga. Pero, sin duda el más notable testimonio de los festejos que por el nacimiento de ese infante preparó el Virrey Duque de Linares es la Esfera mexicana. Solemne Aclamación y festivo movimiento de los Cielos Delineado en los leales aplausos que al feliz Nacimiento del Serenísimo Señor Infante D. Phelipe Pedro... consagró la Muy Noble... Ciudad de México (1714), festejos descritos por José Gil Ramírez, de la orden de San Agustín.

Poco es lo que sabemos de este autor; Beristáin lo hace natural de México y lo reputa de «eruditísimo en Letras Humanas»; añade que «vivió ciego muchos años y falleció por el de 1720». Gil Ramírez fue autor de un «Romance endecasílabo a la Canonización de S. Juan de Dios, premiado e impreso en el
Certamen de 1702», así como de los «Portentos milagrosos del Taumaturgo Eremita S. Nicolás Tolentino, impreso en México muchas veces y últimamente en 1797 y 1804» (Cfr. con Beristáin de Souza, 1819), así como de esa Esfera mexicana de que nos ocuparemos enseguida ${ }^{1}$. Dice allí su autor, con la modestia retórica inexcusable en tales casos, pero sin ocultamiento de su íntima satisfacción, que

para escribir el regio esplendor de tanta fiesta, eran menester penetrantes atenciones de inconnivente ${ }^{2}$ pupila, y hallándome yo dos veces anochecido en replicadas privaciones de vista, pues si la del entendimiento es tan corta que apenas percibe los vultos a las razones, la de los ojos está tan apagada que apenas distinguen las obscuridades a las sombras.

Sin embargo, añadía, al igual que aquella estatua de Menón o Mennón ${ }^{3}$ que recibiendo la luz del sol naciente producía una música maravillosa, así a él, sintiendo el calor «de las lumbres reales de nuestro Infante» se le llenarán de «sonoroso aliento los helado órganos» de la vista y, vencida la «nativa mudez» del entendimiento, «romperá en dulces elocuencias mi lengua». Pero, como tendremos ocasión de comprobar, quizá no todo sea convención retórica en esas hiperbólicas expresiones de Gil Ramírez, porque es en verdad notable la calidad sensorial y lumínica tanto de su prosa como de sus versos descriptivos.

\section{II}

Bien sabemos que las entradas de los reyes en las ciudades principales, así como su nacimiento, bodas, victorias militares, etc., fueron celebradas desde la Edad Media con gran pompa cortesana y regocijo popular, pero fue a partir del Renacimiento cuando tales festejos alcanzaron su plena vinculación con las formas y costumbres del mundo clásico; parte principal de ellos era la erección de arcos triunfales a la romana en homenaje al monarca, los escenográficos desfiles de carros alegóricos, así como las abundantes diversiones gratas al pueblo bajo: comedias, luminarias, mascaradas, corridas de toros, peleas de gallos, carreras de perros y toda suerte de licenciosos fandangos ${ }^{4}$. Los carros triunfales constituyen un género particular de esos refinados y a la vez multitudinarios espectáculos públicos; en efecto, la entrada de los capitanes victoriosos en la Roma imperial, tal como se conocía por los relieves
De la Esfera Mexicana, impresa en 1714 por la Viuda de Miguel de Ribera, la Biblioteca Nacional de México no posee ningún ejemplar; tiene uno la Biblioteca José Toribio Medina de Santiago de Chile, del que hemos obtenido copia microfilmada.

2

Latinismo de conniveo: dormirse, eclipsarse (el sol o la luna), de donde inconnivente=vista no eclipsada.

3

Alude a una de las estatuas colosales erigidas por Amenotep III que al recibir los primeros rayos solares producía una música maravillosa. Es probable que esta referencia a la estatua de Memnón provenga del Oedipus Aegyptiacus de Athanasius Kircher.

Eran tales los desmanes de la "plebe», así en ocasiones festivas como fúnebres, que en 1666 el Santo Oficio erigió «a puerta cerrada»su túmulo para las «exequiales honras» de Felipe IV, a fin de evitar «los enfadosos concursos, estorbos y pareceres de un abierto vulgo». Cfr. María Dolores Bravo Arriaga (2001).

Astronomía espectacular y extravíos de la gula en un festejo novohispano del siglo XVIII

JOSÉ PASCUAL BUXÓ 


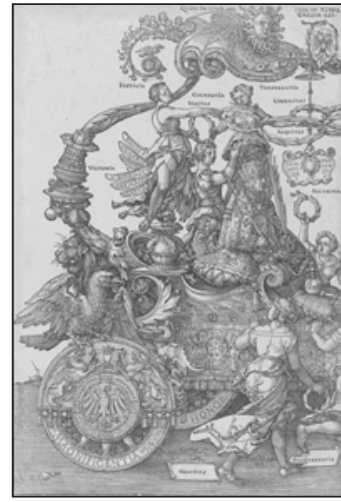

Gran carro triunfal de Maximiliano, Durero (fragmento)

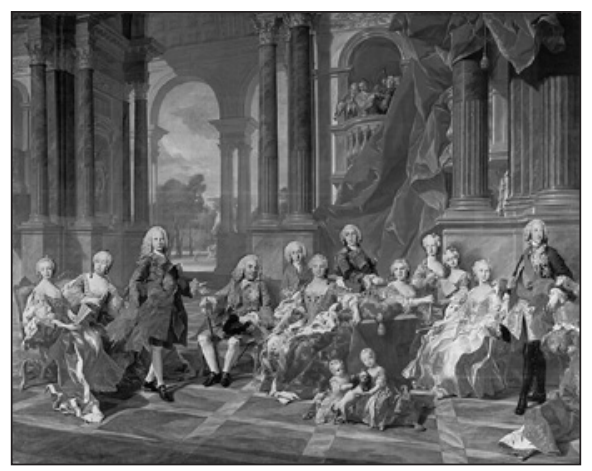

La familia de Felipe $V$, de Van Loo, 1743

5

En 1725, Villerías publicó el Llanto de las estrellas al Ocaso del Sol anochecido donde también recurrió a la astronomía emblemática.

6

Autor de Las tres Gracias, manifestadas en el crisol de la lealtad de México... Fiestas por el natalicio del mismo infante Felipe Pedro (1713).

7

Puede consultarse la moderna edición, prologada por Francisco de la Maza, del Reportorio de los tiempos e Historia natural de esta Nueva España (1991 [1 ra. ed. 1948])

Astronomía espectacular y extravíos de la gula en un festejo novohispano del siglo XVIII

JOSÉ PASCUAL BUXÓ y relatos antiguos, fue el modelo en el cual se basaron esos artificiosos aparatos simbólicos. A Jacob Burkhardt debemos algunas páginas memorables sobre el asunto; así, pongamos por caso, las referentes a la entrada de Alfonso el Grande en Nápoles (1443) quien, en un trono instalado sobre un carro gigantesco, iba acompañado de un cortejo de jinetes lujosamente ataviados y seguido de «otro imponente armatoste» sobre el cual se asentaba un fingido Julio César coronado de laurel, «que en versos italianos iba explicando todas las alegorías» desplegadas en el cortejo (Cfr. con Jacob Burkhardt, 1942). También las carnestolendas, con su multitud de disfraces y comparsas, fueron espacio apropiado para que se hiciera la adaptación festiva de los mitos antiguos; así, cuenta Burkhardt, en los carnavales romanos y florentinos de los siglos XV y XVI era indispensable el desfile de carrozas fantásticas sobre las cuales se asentaban diversas figuras alegóricas: «la Envidia con cuatro caras con gafas en una misma cabeza; las tres Parcas; la Prudencia en un trono sobre la Esperanza y el Temor, que yacen encadenados a sus pies; los cuatro elementos, las edades de la vida», etc. etc. Sabemos cuál es la naturaleza de ese fenómeno político-social, auspiciado regularmente por los poderes establecidos, según el cual a las ceremonias de sacralización de los príncipes ha de seguir el desfogue carnavalesco de los míseros y oprimidos: orden espectacularmente impuesto y caos brevemente tolerado, serán también apreciables en el mundo novohispano y, más singularmente, en la aludida Esfera mexicana, según luego veremos.

Para los «festivos alborozos y comunes alegrías» de la corte mexicana por el nacimiento del infante Felipe Pedro, el erudito Gil Ramírez, en colaboración con otros ingenios de la corte mexicana, singularmente su discípulo José de Villerías ${ }^{5}$ y su amigo Ambrosio de Orcolaga ${ }^{6}$, imaginó un deslumbrante dispositivo simbólico, según el cual serían cada una de las divisiones de la esfera mundana: el Primer móvil, el Firmamento y los siete cielos planetarios quienes, a lo largo de trece días, irían aclamando por turno al infante. «Mas ya oigo -escribía Gil Ramírez en anticipada justificación de su idea alegórica- que pregunta la discreción escrupulosa, si no es la crítica curiosidad, por qué han de ser los Cielos los que aplaudan este nacimiento»; y respondía cortesanamente: porque «sujetos tan elevados no quedan dignamente aplaudidos, menos que por tan altos Panegiristas». La idea que subyace en toda la disposición alegórica del festejo del infante se funda en la correspondencia establecida entre la compleja estructura de la máquina universal respecto de los componentes del bajo mundo, esto es, los hombres y el lugar que éstos ocupan dentro de la jerarquía social, de modo que los estados mundanales se asimilan a la estricta organización de los cielos: la sociedad, como el universo, es una máquina establecida $a b$ aeterno en la cual cada uno de sus miembros debe desempeñar una función intransferible y necesaria con el fin de asegurar, por una parte, la inmutabilidad del universo y, por otra, la incolumidad de la república.

Para la cabal comprensión de ese magno programa alegórico será menester recordar con brevedad la figura o mapa del universo tal como fue ideada por los filósofos de la Antigüedad y, en particular, por el alejandrino Ptolomeo. Apelaremos para ello a nuestro Henrico Martínez, autor de un Reportorio de los tiempos e Historia natural de la Nueva España, publicado por el autor en 1606 en su propia imprenta de la Ciudad de $\mathrm{México}^{7}$, y cuya exposición del «mundo en general y en particular de la región celeste», siguió siendo la más recibida aún mucho después de la «revolución copernicana», esto es, de la aceptación en los círculos científicos del cambio del paradigma geocéntrico por el heliocéntrico.

El universo mundo está compuesto de dos partes distintas: una celeste y otra terrestre; la primera se extiende desde el cóncavo de la luna hasta el primer móvil; debajo del cielo de la Luna hasta el centro de la tierra, que lo es también del universo, se instala la llamada región elemental, sobre la que ejercen su permanente influjo las luces y los movimientos de los astros. Hay entre los elementos y los orbes celestes una particular correspondencia, pues todo el universo ha sido creado para servicio del hombre; de ahí que éste se asemeja a los ángeles en el entendimiento; al Sol, en el corazón; a la Luna en el cerebro; en el bazo a Saturno; en el hígado a Júpiter; en la hiel a Marte, y por el mismo modo a los otros planetas, razón por lo cual los filósofos llamaron al hombre «mundo abreviado». 
Supusieron los astrónomos en la región celeste -explicaba Henrico Martínez- «diez orbes distintos»; el primero de ellos, considerado desde nuestra perspectiva terrena, es el de la Luna; el segundo, de Mercurio; el tercero, de Venus; en el cuarto se mueve el Sol, en el quinto Marte, en el sexto Júpiter y en el séptimo Saturno; «al octavo Cielo, llamado firmamento, es adonde está la multitud de estrellas fijas». Y sobre todos ellos imaginaron otros dos cielos con el fin de explicar los movimientos planetarios, y así postularon la existencia de una novena y décima esferas: «el movimiento tardío que las estrellas hacen sobre los polos del zodíaco, de occidente en oriente, se atribuye a la novena esfera»; la décima-superior a todas y que determina los movimientos del Sol y de la Luna- es el Primer Móvil, y sobre este motor universal, está el Empíreo, morada de los dioses antiguos y ya declarada sede de la divinidad cristiana. Añadamos una información complementaria: atravesando el universo, en posición oblicua al eje de la esfera, está el círculo zodiacal, debajo del que se mueve el Sol; «divídese este círculo -anota Henrico Martínez- en doce partes iguales que se dicen signos y a cada uno de ellos dieron los antiguos el nombre de algún animal o de otra figura» (Aries, Tauro, Géminis, Cáncer, León, Virgen, Libra, etcétera) en correspondencia con el significado atribuido a las estrellas consteladas. Y como la tierra «sea un receptáculo común de todas las influencias del cielo», los peritos en astrología saben que en la hora de su nacimiento, cada ser humano participa, no sólo de la calidad de su signo zodiacal ascendente, sino «también de la influencia de toda la máquina celeste».

\section{III}

El primer día de los trece que ocuparon los festejos, correspondiente al Empíreo cristiano de conformidad con la trama alegórica discernida por Gil Ramírez y sus colaboradores, tocó a la Iglesia Metropolitana de México celebrar una solemne misa de acción de gracias; por la noche hubo luminarias en el palacio virreinal, claro antecedente de las pirotecnias nacionalistas de nuestro zócalo septembrino. Fingieron los «étnicos» o gentiles -explicaba Gil Ramírez- «una florida Estancia, Vergel ameno y delicioso Parayso donde, desatadas las almas, gózanse entre incomparables delicias»; pero erraron como gentiles, puesto que -de conformidad con esta alegórica teología- «no hay más Elisios que los que plantó el hortelano Divino en el supremo Cielo, Real Palacio del más soberano Monarca», a cuyo «florido Hemisferio», sirve de Sol el luciente cordero Jesucristo.

El mecanismo semiótico utilizado para el establecimiento de estas retóricas correspondencias es, pese a su aparatosidad cósmica, verdaderamente simple: se trata siempre de ponderar los atisbos del «ciego» gentilismo, esto es, partir de sus mismos paradigmas culturales (en este caso su peculiar imagen del mundo) pero corrigiendo en ellos los «errores» en que había incurrido respecto de los dogmas de la teología cristiana. Así, pues, a este "Elisio ameno», sede de la divinidad, se corresponden en la tierra «los templos que la Cristiandad erige» y, por tal razón, en el festejo novohispano del que tratamos, tuvo la Iglesia Metropolitana la primacía en celebrar la «pompa festiva de rendidas gracias que se consagraron a Dios por el feliz natal de nuestro glorioso Infante». Se adornó el templo con incontable número de «bujías artificiales» que, según se dice, evocaban las azucenas del Empíreo; se echaron a vuelo las campanas y los indios se unieron al regocijo general «repicando ternos de chirimías»; como era de preverse, terminó el día con la «Oración Angélica». Por la noche, frente de la fachada principal de la Iglesia metropolitana, «se quemaron nueve distintas invenciones de fuegos», entre ellas «un vistoso volador», que es antiguo artificio de los naturales del Reino, y el cual, con sus «compasadas vueltas», fue vivo trasunto de su original, esto es, del Primer móvil o décima esfera. Advirtamos de una vez que la conspicua presencia de indios y castas en estos y otros festejos públicos novohispanos es claro indicio del propósito de sus organizadores no sólo de reconocer públicamente el mérito o la extrañeza de las costumbres de la tierra, sino
Astronomía espectacular y extravíos de la gula en un festejo novohispano del siglo XVIII

JOSÉ PASCUAL BUXÓ 
La participación de los indios era, política e ideológicamente, indispensable en todos los festejos y honras fúnebres celebrados en la Nueva España en su descripción del Túmulo imperial (1560), Cervantes de Salazar indica el sitio que les fue asignado "así a los Señores como Gobernadores, Alcaldes y Regidores de las cuatro cabeceras》 (México, Tacuba, Texcoco y Tlaxcala), y alude expresamente a los macehuales que tomaron parte activa en la procesión. Cfr. Francisco Cervantes de Salazar (1972). Por su lado, el P. Pedro Morales, en la carta en que dio detalladas noticias de los festejos ordenados en 1578 por la Compañía de Jesús para celebrar el envío que les hizo el Papa Gregorio XIII de numerosísimas reliquias, insistió una y otra vez en el gran número de naturales que asistían a las ceremonias $y$, en particular, al éxito del «buen espíritu» con que los propios jesuitas los guiaban en su devoción. Cfr. Carta de Padre Pedro de Morales (2000). Está claro que si los indios caciques pudieron sentirse lateralmente incorporados a la sociedad criolla, el pueblo bajo continuó en la servidumbre, esto es, permaneció en su propia condición antes y después de la conquista. El esquema de las jerarquías sociales ordenadas en función de la estructura ptolemaica del universo fue -y aun sigue siéndolo, oculto bajo los designios de ciertas fuerzas políticas de nuestro mundo actual- un persuasivo fantasma ideológico.

La explícita vinculación simbólica del águila imperial con los polluelos de la expulsada águila mexicana la había establecido precedentemente Isidro de Sariñana en su Llanto de Occidente...fúnebres demostraciones... en las exequias de Felipe IV, de 1666 , ponderando la clemencia de los reyes hispanos, cuyos afectos paternales convirtieron a los adoptivos (los indios) en hijos naturales.

Astronomía espectacular y extravíos de la gula en un festejo novohispano del siglo XVIII

JOSÉ PASCUAL BUXÓ del designio criollo de incorporar a las dos repúblicas de españoles e indios en un mismo patrón de identidad americanas.

Si el primer domingo de festejos correspondió a las autoridades religiosas constituirse como representes terrenos del Empíreo, el siguiente día se destinó para que las autoridades civiles, esto es, la «Nobilísima Ciudad de México», se viera homologada con el «Primer Moble», esfera superior que sirve de "imán de los restantes Orbes», pues es ella quien «arrastra arrebatadamente tras de su veloz movimiento toda la voluble máquina de los inferiores Cielos». ¿Qué mejor metáfora para designar el omnímodo poder virreinal que ese motor inmóvil de todos los estamentos de la sociedad novohispana, a la vez imperativo y suave, justo y prudente, que es como querían y debían verlo sus panegiristas? Así, el conjunto de corregidores, alcaldes, regidores, caballeros de las órdenes de Santiago o Calatrava... (cuyos nombres registró puntualmente Gil Ramírez, como queriendo inscribirlos en el padrón glorioso de la urbe mexicana) participaron de una lucida procesión, jinetes en hermosas y bien enjaezadas cabalgaduras, que con su bizarría hiperbólica «dejaron atrás la antigua destreza de los Lapitas». Y más, cuando que sus vestidos -simbólicamente acordes con el nuevo linaje de la monarquía- combinaron los gustos de la moda francesa con la española. A nuestro autor que, en el fondo, no parecía muy conteste con estos cambios dinásticos, comenta que dicha «composición» de los vestidos «en otro tiempo pudo parecer monstruosa, y en éste fue indicio del hermanado enga[r]ce de una y otra nación generosa, y moda que continuó discreta la política en lo restante del paseo». Pero fueran cuales fueren los gustos indumentarios de quienes habían nacido bajo el imperio indiscutido de los Austria, la verdad es que esa mezcla de vestidos y linajes era ya el símbolo de una nueva e indiscutible realidad política.

Teniendo la Ciudad de México por blasón al «Aguila generosa», que fue signo de las antiguas armas mexicanas y era ahora «insignia» del dilatado imperio español, no podía dejar de convocar a la celebración del infante Felipe Pedro a los «nobles pollos de las ciudades que ocupan el espacioso nido de este Americano mundo» 9 . A efecto de que las más insignes ciudades de la Nueva España se hicieran presentes en el festejo, ostentando los «frutos con que próvido el Cielo enriqueció sus climas», se ideó y construyó un «hermoso Plaustro», que seguía a la comitiva de las autoridades civiles.

En la popa de ese carro triunfal «en metáfora de Nave», se tendió un pabellón azul y plata cuya luminosidad era «envidia»-dice Gil Ramírez-del sol y las estrellas; debajo de ese fingido cielo deslumbrante, en un sitial en forma esférica, se pintaron, del lado derecho, la imagen del Rey Felipe V; al centro, la de la reina María Luisa Gabriela de Saboya, con el infante Felipe Pedro en su regazo, cual si figurara a Venus con su Cupido recién nacido; y a la izquierda, el retrato del Príncipe de Asturias, Luis Felipe, sucesor inmediato al trono, todos ellos vestidos a la moda francesa. A los costados del bajel rodante se colocaron diversas estatuas de talla que representaban las principales ciudades del Reino, las cuales ofrecían a sus majestades su lealtad y sus riquezas. La ciudad de México dedicaba «un corazón ardiendo en amor sobre la nieve de una azucena», patente alusión a los dos linajes que se conjuntaban en la nueva familia real española y, en especial, a su vital regeneración debida al nuevo implante de sabia francesa. Desataba la alegoría Gil Ramírez en el siguiente soneto, que no dejaba dudas acerca de la fidelidad, por no decir subordinación, de los monarcas españoles a los designios de la corona francesa:

Este regio pimpollo dominante, Ardiendo nieves y nevando ardores,

Es Ethna vegetable entre las flores

Que oculta en viva nieve ardor fragante.

La vida debe a un corazón constante;

Éste le infunde alientos en olores,

$Y$ a sus Esferas cinco de candores

Oculta sirve de amoroso Atlante.

Qué mucho pues que a vuestros pies presente

(Lis generoso) mi lealtad nativa

Un corazón que os ame reverente.

Porque si a tanto influjo vidas liba,

No el corazón a la azucena aliente,

Sí el corazón por la azucena viva.

Seguía la ciudad de Veracruz, "primera fundación de este Reyno», cuyo simulacro sostenía en las manos un castillo que figuraba el de San Juan de Ulúa y una «tarja» o escudo en que «hablaban» por ella un mote latino y una octava castellana en que se ponía de manifiesto la efectividad de esa guarnición 
militar contra las incursiones piráticas. Decía así el mote de esta composición emblemática: Infantis magno firmabor, robore planta. Y así decía la glosa en esta octava:

Este de Marte Alcázar elevado, Militar Templo de guerrera Diosa, Horror tonante de Pyrata osado, Guarnecido de gente valerosa,

Que en planta estriba de arrecife armado,

De vuestro pie la estampa generosa

Besa, porque si alcanza dicha tanta,

Hallará en vuestro pie más firme planta.

Otras estatuas bordeaban el carro triunfal cuya disposición era semejante a la primera, pues cada una de ellas sostenía igualmente en las manos un objeto significativo y una tarja con un doble texto compuesto de un mote latino y una estrofa castellana. Se aprecia claramente en esta disposición la estructura emblemática de ese dispositivo alegórico, pues si la figura tallada corresponde obviamente a la res picta de los emblemas, los textos inscritos o suscritos cumplen la misma función que corresponde en ellos al mote que encabeza la imagen y a la glosa o epigrama que declara su significado alegórico-conceptual. No sería oportuno dar cuenta pormenorizada de todas y cada una de las ciudades novohispanas (México, con su corazón ardiente; Puebla, con su tecalli o «mármol indiano»; Valladolid, con las espigas de Ceres; Guadalajara, con su rubio metal; Mérida, con sus panales; Antequera, con su «múrice indiano»; Zacatecas, con su plata, y Durango con sus vides), baste decir que -en la lengua hiperbólica del relator- eran todas ellas de tan perfecta factura que «pudieran ser fatigada tarea de Phidias».

Una vez llegada toda aquella «alegre variedad al Real Palacio, en cuyos balcones esperaba gozoso el Excelentísimo Señor Duque de Linares, Virrey de esta Nueva España», salió «por un escotillón del buque del Carro» -esto es, por una tapa corrediza disimulada en el suelo de la fingida nave- un «gallardo mancebo» que, pidiendo silencio, comenzó a recitar una loa en la que describía con mayor aliento los atributos de cada una de las estatua y de las ciudades que de ellas representaban. Era costumbre entonces que, para ser recitada ante el arco por el que hacían su entrada triunfal arzobispos o virreyes, $\mathrm{o}$ frente a un plaustro también repleto de figuras y textos alegóricos, el autor del programa alegórico compusiera una loa explicativa; así por ejemplo, el Neptuno alegórico, arco ideado y descrito por Sor Juana Inés de la Cruz para la entrada del virrey Marqués de la Laguna en la Ciudad del México, en 1680, concluye con la loa en la cual -en eficaz ejercicio de descripción ecfrástica- fue explicando la traza y significación de cada una de las figuras representadas en el arco:

Aquel lienzo, Señor, que en la fachada

Corona airosamente la portada...

En el otro, Señor, que a mano diestra

En aquella anegada ciudad muestra...

Allí se ven los griegos inhumanos

Dando alcance a los míseros troyanos...

Procediendo de igual modo, Gil Ramírez compuso una loa descriptiva y exegética de todas las figuras de aquel carro triunfal en la que recoge y amplía las ideas y las imágenes que antes vimos aparecer en las octavas que servían de glosa conceptual de las figuras emblemáticas, pero que en esta composición son afrontadas con mayor libertad y abundancia. Pongamos un ejemplo, el segmento de la loa relativo a Mérida. En la respectiva octava, destacó el autor el don principal de esa ciudad, los panales de cera y miel, y forjó allí una sugestiva imagen de la «abeja exploradora» que, por moverse en un «piélago de flores», se trasmuta en un metafórico «buzo errante/ de las perlas que grana limpia Aurora»; pero en la loa, la «abeja errante» ya no se nos presenta como exploradora de los océanos floridos, sino como "pirata alado en piélago fragante». Como se ve, las retóricas exigencias de la poesía cortesana no ocultaban, antes bien, incluían en la guirnalda de sus versos pastorales, la constante amenaza de las incursiones piráticas en las ciudades ribereñas del Seno mexicano:

Oigamos un poco más acerca de la ciudad de Mérida:

Esta, pues, opulenta

Noble Ciudad a vuestro culto atenta

Os rinde (heroico dueño)

De su crecido amor corto diseño,

Con afecto leal y decoroso,

Compuesto de destellos

Que Flora en granos atesora bellos,

$\mathrm{Y}$ en fragatas de rosa

Comercia con el Cielo venturosa

Por océanos de púrpura y de nieve,

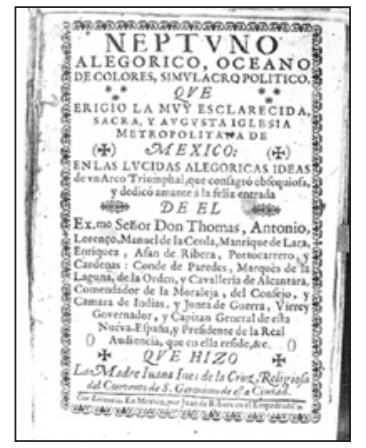




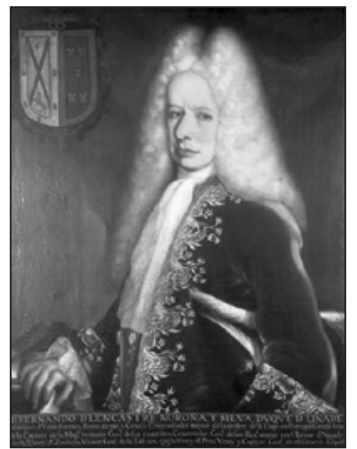

Retrato del virrey duque de Linares

10

Siendo casi imposible la consulta de algún ejemplar de la Esfera mexicana, el lector podrá acudir a la antología de Poetas novohispanos. Primer siglo (1942), pp 174-183.
Que a blandos soplos el Favonio mueve,

$Y$ abeja susurrante,

Pirata alado en piélago fragante

O le roba o le liba

Con ambiciosa sed, con ansia viva,

Para hacer de este robo, argumentosa,

Ya dulce miel, ya cera luminosa,

Que en llama refulgente

Arde en las aras, culto reverente.

Cera, en fin, os dedica,

En otra mejorada que fabrica

Dulce abeja oficiosa

En la fe de su pecho fervorosa,

Que atenta a vuestro culto y a su fama

Eterno aliento su implacable llama.

(Méndez Plancarte, 1942, pp. 174-183)10.

Siendo tan patentes los efectos de percepción sensorial en muchos de los versos que anteceden, ¿quién pensaría que fueron escritos por un poeta ciego? De atenernos a Beristáin, se diría que Gil Ramírez fue vidente en su infancia o juventud y que la ceguera lo atacó cuando ya conservaba el firme recuerdo de lo que son luces, colores y volúmenes. Por ahora solo contamos con el testimonio de su escritura plena también de luminosidad y movimiento que evoca-quizá más allá de los modelos reconocibles: Virgilio, Garcilaso y el omnipresente don Luis de Góngora- una sutil competencia poéticopictórica que era, por otra parte, exigencia estética a la que debía ceñirse toda descripción literaria. Sea como fuere, en la evocación de los dones ofrecidos por la ciudad de Mérida al recién nacido Infante, es decir, los fulgores de la cera y la miel; la reverberación de las luces estivales; las flores movidas por el cálido Favonio, comparables a océanos de "púrpura y de nieve», en fin, la sensación de lienzo pintado que se desprende de éste y otros muchos momentos de la loa, nos persuaden de que si Gil Ramírez tenía la vista tan «apagada» que no le permitía distinguir las luces de las sombras, su fantasía, en cambio, estaba tan sobrada de luces, que era capaz de reconstruir verbalmente -apoyado en los dechados literarios recibidos- los más luminosos paisajes y describir con pormenor los más bizarros cortejos de aquellas lucidas fiestas en honor del infante Felipe Pedro, el primer Borbón hispano.

\section{IV}

Astronomía espectacular y extravíos de la gula en un festejo novohispano del siglo XVIII

JOSÉ PASCUAL BUXÓ sidad -como representante de las «luces del Firmamento y Minerval aparato»- con la numerosa concurrencia de sus «elocuentes retóricos», «perspicaces astrónomos», «agudos filósofos» y toda la cauda de estudiantes, bachilleres, licenciados, maestros y bedeles que acompañaban un «suntuoso carro» sobre el que se colocó una «cuna de cristal, con respectos de trono", donde se mostraba la imagen del Infante, y sobre él las del sol y de un león, como queriendo significar -contra las evidencias de la historia- que las más remotas naciones habrían de temer el «valiente rugido del León castellano». En contraposición con el riguroso aparato ceremonial de los festejos anteriores, los días cuarto, quinto y sexto se destinaron a regocijos populares y, así, evocando las figuras del Zodíaco, se dieron corridas de toros, carreras de perros y peleas de gallos, todo ello narrado con notable puntualidad por Gil Ramírez, socorrido sin duda por sus atentos informantes.

El día séptimo salió el Real Protomedicato de México con un carro triunfal dedicado a los «lucimientos de Apolo», el mayor planeta, cuya «variedad de movimientos y diverso temperamento de sus rayos» causan las mudanzas de los humores, «ordinariamente proficuas a la conservación del linaje humano». Esta facultad, recordaba Gil Ramírez, se divide en tres «orbes» o especialidades: la Dietética, la Farmacéutica y la Quirúrgica; de suerte, pues, que médicos, boticarios y cirujanos desfilaron acompañando un carro triunfal que transportaba una estatua de Apolo sentado en su trono y rodeado de sus cuatro «doctísimos hijos y famosos príncipes de la medicina: Hipócrates, Galeno, Avicena y Mesue», todos ellos ilustrados con sus correspondientes jeroglíficos y octavas que declaraban su semiencubierto significado.

El segundo festejo del día correspondió al «popular alborozo de la plebe». Fue costumbre de los antiguos, apunta el autor, celebrar convites públicos en honor de los «días geniales de las personas insignes»y, para ello, concluida la manifestación pública de los guardianes de la salud con la loa que se pronunció frente a los balcones del Virrey, determinó el duque de Linares que se erigiese en medio de la Plaza un «opíparo Paraíso de la gula» en forma de pirámide cónica, en cuya cima se colgaron apetitosos manjares: chorizos, morcillas, salchichas, tocino, melones, chirimoyas, chayotes, piñas y camotes, y en 
su base se ataron pavos, palomas, gallinas y hasta una «temerosa terneruela». Se trataba, pues, de una formidable cucaña destinada a darle gusto al pueblo bajo. Gil Ramírez dice no haber sido él, sino un anónimo "curioso» -esto es, un esmerado poeta, colaborador suyo- quien describió en octavas ese formidable Paraíso gastronómico. Es evidente que el sagaz Virrey quiso darle al vulgo satisfacciones más adecuadas a su mísera condición y, así, hizo alternar con los desfiles de los carros triunfales, ricamente plagados de erudiciones astronómicas, míticas y emblemáticas, no sólo las sangrientas corridas de toros y peleas de gallos -que tanto deleitaban también a los individuos de las clases privilegiadas- sino además una gran cucaña atestada de manjares que incitaban el gusto de los macehuales.

La autoridad alternó sabiamente las manifestaciones gloriosas de un orden político y social reciamente establecido con una breve fuga carnavalesca que diera a los desamparados la ocasión de la boruca, el hartazgo y la risa. Mientras los individuos de la plebe trepaban trabajosamente por el resbaladizo cono ensebado, desde los balcones de palacio, los cortesanos reirían de las grotescas contorsiones y aparatosas caídas de los cucañeros, que en esta ocasión se disputaban, sin temor y al descubierto, tantos beneficios a costa ajena. Pero no es éste, por cierto, un caso comparable con las comilonas a mandíbula batiente de los personajes de Rabelais, es decir, un simulacro de la relación más o menos justa o proporcionada entre la realización de un trabajo y la obtención del alimento como «última etapa victoriosa» del esfuerzo personal, que diría Mijail Bajtin (1974); ni es tampoco un banquete ceremonial en el que los individuos de un grupo entran en relación eficaz y simbólica con el mundo y consigo mismos; es más bien el asalto carnavalesco, permitido por única ocasión, a una riqueza reservada a los otros, pero que ahora -en las «graciosas» circunstancias de haber nacido un Infante real $y$ con el fin de mostrar precisamente el inmenso poder y generosidad de la monarquía- se concede a los socialmente ínfimos, testigos inveterados de las hambrunas crónicas en la Nueva España, el placer salvaje de disputarse libremente los trozos desgarrados de unos alimentos milagrosamente puestos a su alance.

Algo de esto deja entrever el «curioso» poeta autor de la descripción de esta «Pirámide» incitante, pues no omite decirnos que, después del asalto, «ni la ruina quedó del edificio", a lo que añade Gil Ramírez este comentario revelador: «así fue, pues aun los maderos de que se componía [la pirámide], fueron, aun cuando más pesados, ligera carga a los hombros de la necesidad ambiciosa». Oportunidad única para esos desesperados que cargaron con todo lo que podía aliviar su crónica miseria, sabedores de que allí terminaba para ellos la justicia carnavalesca de un mundo transitorio. Sin embargo, lo que más parece importarle al relator, colocado en la doble perspectiva de un alejamiento burlesco y de un orgullo criollo y regionalista, es poner los productos americanos en pie de igualdad $\mathrm{o}$, inclusive, en ventaja sobre las peninsulares, como ya lo habían hecho más de un siglo antes algunos poetas sevillanos residentes en México, Juan de la Cueva entre ellos, quien -contrariamente al menosprecio que hacían los gachupines de las comidas de la tierrasupo gustar de todas las «frutas naturales,/ el plátano, mamey, guayaba, anona...», no menos que del pipián, que "es célebre comida, / que al sabor dél os comeréis las manos» ${ }^{11}$.

He aquí las octavas que describen ese monumental

Paraíso de la gula.

Sobre fornido y circular cimiento, hermoso objeto de atención ayuna, se levantaba acongojando el viento fábrica primorosa y oportuna; su vuelo mantecoso, si opulento, al Sol peligro fue, riesgo a la Luna, pues temieron manchar en su cabeza aquél sus rayos y ésta su pureza.

Cuanto ganado a espaldas de la nuca cuchillo sufre, que su aliento beba, plato aquí fue de popular boruca, si desquite a la mano que le ceba. Desierto Metepec, yerma Toluca, moderna Extremadura a España Nueva, lloraron imitando ondas al Nilo las sartas de chorizos hilo a hilo.

Sabroso el pavo, honor de cuanto vuela, guloso el apetito convidaba; la gallina, el carnero y terneruela y el fiero toro de arrogancia brava; el tierno recental, niño de escuela, sin dejar de balar deletreaba; piaban las aves con afán baldío, piedad faltando (como siempre) al pío.
11

Léanse algunos fragmentos de su «Epístola al Lic. Sánchez de Obregón, primer corregidor de México» en Alfonso Méndez Plancarte (1942)
Astronomía espectacular y extravíos de la gula en un festejo novohispano del siglo XVIII 
12

Circuló en papeles manuscritos y se imprimió en la sección de «Poesías líricas» del Segundo volumen de las obras de soror Juana Inés de la Cruz, Madrid, 1692.
Astronomía espectacular y extravíos de la gula en un festejo novohispano del siglo XVIII

JOSÉ PASCUAL BUXÓ
No produjo en el valle o en la sierra,

fruta el suelo que fuese reservada:

el melón, de la vida armada guerra,

y el plátano de Jerjes, paz amada;

la reina chirimoya, que esta tierra

al imperio usurpó de la granada;

recia la piña, indócil el chayote,

fresca sandía y hartador camote.

Salchichas y morcones (nada en vano)

séquito eran del lomo y el tocino,

fe de bautismo a todo fiel cristiano,

y asco del agareno y palestino;

pato de la laguna, cortesano,

paloma del tejado también vino,

con blanco pan, con oloroso queso

de escolástica hambre carne y hueso.

Hizo la seña a la invasión precisa

de éste que, a ser de talle algo más breve,

igualara el sepulcro de Artemisa,

el que acrecienta el número a las nueve,

$y$, encrespando narices a la risa,

turba embistió la codiciosa plebe;

muchos van, pocos no se precipitan,

suben unos, caen otros, todos gritan.

No así de inmundo enjambre plaga espesa

admiró en su palacio el rey de Egipto,

como el Virrey de México en la gruesa

fábrica del espléndido distrito;

excedióse esta vez la misma priesa

(cuál mosca, cuál moscón, cuál ya mosquito)

y en un instante imperceptible al juicio

ni la ruina quedó del edificio.

Para los poetas novohispanos de principios del siglo XVIII, el Primero sueño de Sor Juana Inés de la Cruz era de sobra conocido ${ }^{12}$, de suerte que no debe sorprendernos que en la estrofa inicial del Paraíso de la Gula se aluda en tono burlesco a la imagen sobrecogedora de aquella "piramidal, funesta, de la tierra nacida sombra...» que -en el texto de Sor Juana- amenaza con oscurecer la luna y las remotas estrellas y que, dentro del general paradigma astronómico de los festejos que nos ocupan, el «vuelo mantecoso» de la pirámide gastronómica amenazase también con manchar ignominiosamente los rayos del sol y la blanca castidad de la luna. Se haría con esto una intencionada alusión al grupo de los privilegiados espectadores quienes, resguardados en sus altos balcones, contemplarían entre el disimulado temor y el abierto desdén los exce- sos a que podía llegar la cómica violencia de los desheredados. Pero hasta allí llegan las posibles remembranzas del poema sorjuaniano, pues el propósito del autor del Paraíso de la gula no es el de hacer la parodia de un poema «heroico» y erudito, sino el de darnos una descripción jocosa y a la vez incitante de todos los comestibles que se colocaron en aquella piramidal cucaña para el fugaz y tormentoso disfrute de los macehuales. Así, pues, a partir de la segunda octava, da inicio ese bodegón literario en que se combinaron la naturaleza viva y la naturaleza muerta, es decir, la mezcla de frutos y animales con los alimentos ya guisados.

Es notable en esta descripción la eficacia y variedad del sistema descriptivo de los elementos evocados, por medio del cual se ponen de relieve tanto sus cualidades sensibles como afectivas. Así, por medio de un significativo sistema de epítetos se precisa la especificidad (semántica y aun gastronómica) de los elementos mencionados; vgr. "recia la piña», «indócil el chayote», «bartador camote» o, en otras ocasiones, a través de la combinación de epítetos con frases sustantivas en aposición: «sabroso pavo, honor de cuanto vuela»; «el tierno recental, niño de escuela»; o también por medio de la doble determinación de un núcleo sustantivo con epítetos y frases sustantivas: "el fiero toro de arrogancia brava». Con el doble fin de evocar los usuales tópicos de la erudición clásica y de darle mayor plasticidad sintáctica al poema, se acude a la doble determinación de los núcleos sustantivos, de manera que a éstos se añade una frase en aposición que los instala en un espacio semántico de carácter ya sea familiar o ya erudito; v. gr. «el tierno recental, niño de escuela» o «el plátano de Jerjes, paz amada».

Ese tan apreciado recurso a la alusión de textos memorables $-o$, si se quiere, de noticias acerca de la historia antigua $\mathrm{o}$, incluso, de la casera realidad cotidiana- puede desarrollarse en frases de estructuración más compleja; así por ejemplo, al ponderar con hipérbole irónica la talla descomunal de la pirámide gastronómica, se dice que, de haber sido algo más chica, «igualara el sepulcro de Artemisa», y cuando se trata de caracterizar el destructor embate que dio la plebe a la cucaña, se la compare a la «plaga espesa» de moscas y mosquitos que destruyó el «palacio del rey de Egipto». Antes, cuando se hizo mención del lomo y el tocino, éstos fueron calificados como «fe de bautismo a todo fiel 
cristiano/ y asco del agareno y palestino»; y cuando se trató del «blanco pan» y el «oloroso queso», se asociaron con el hambre tradicional de los estudiantes de las Escuelas -cuyo modelo inolvidable está en el Buscón de Quevedo-, de modo que pan y queso se constituyeran, con metáfora teológica, como su verdadera sustancia, esto es, su carne y sus huesos.

En la octava final del poema es donde se muestra con mayor énfasis su carácter burlesco y, con ello, los contradictorios sentimientos de menosprecio y fascinación que sobre los gobernantes y letrados novohispanos podía ejercer aquella plebe, sobreviviente degradada de una nación poderosa y temible. La burla no es sólo una forma despectiva del ataque, sino además la embozada defensa de un superior ante la amenaza del temido trastrocamiento de las jerarquías universales; así, será preciso apaciguar al menesteroso con las dádivas de la caridad o aun de permitirle una libertad pasajera y ficticia mediante el trastorno carnavalesco del orden social imperante. No creo exagerar si digo que esa imponente dádiva gastronómica del virrey duque de Linares a los hambrientos de la gran Ciudad de México tuvo el carácter de un verdadero y doble simulacro: por una parte, fue expresión simbólica del poder y magnanimidad con que se presentaba a sus súbditos aquella monarquía que conquistó y seguía manteniendo sujetos a los naturales de la tierra; por otra parte, el total arrasamiento de esta pirámide fue signo subliminal de otra gran catástrofe: la destrucción por parte de los propios indígenas de aquella imagen degradada de su idolatría ancestral. ¿Lo pensarían así Gil Ramírez y sus colaboradores? La innegable competencia de los intelectuales barrocos en el uso de los sistemas simbólicos, tan extendidos en su tiempo, nos permite suponer que así sería.

\section{Bibliografía}

Bajtin, Mijail (1974), La cultura popular en la Edad Media y en el Renacimiento. Madrid, Barral Editores.

Beristáin de Souza, José Mariano (1819), Biblioteca Hispanoamericana Septentrional, En México, Oficina de Alexandro Valdés.

Bravo Arriaga, María Dolores (2001), El discurso de la espiritualidad dirigida, México, UNAM, (Estudios de Cultura Literaria Novohispana, 16).

Burkhardt, Jacob (1942), La cultura del Renacimiento en Italia, Buenos Aires, Editorial Losada.

Carta de Padre Pedro de Morales (2000), Beatriz Mariscal Hay (ed.), México, El Colegio de México.

Castro, Octavio (1998), Sor Juana Inés de la Cruz y el último de los Austrias, México, Universidad Nacional Autónoma de México y Universidad Veracruzana.

Cervantes de Salazar, Francisco (1972), México en 1554 y Túmulo imperial. Ed. pról. y notas de Edmundo O’Gorman, México, Editorial Porrúa, («Sepan cuántos», 52).

Cruz, Sor Juana Inés (1955), Obras completas, III, Autos y Loas. Edición, prólogo y notas de Alfonso Méndez Plancarte, México, Fondo de Cultura Económica.

Méndez Plancarte, Alfonso (1942), Poetas novohispanos. Primer siglo (1521-1621), México, Ediciones de la Universidad $\mathrm{Na}$ cional Autónoma.

Fecha de recepción: 14/02/2013

Fecha de aceptación: 20/03/2013 